Supporting Information

\title{
Rapid one step fabrication of hydrophilic hierarchical porous PDMS with negative piezopermittivity for sensing and energy storage applications
}

Chithra Parameswaran ${ }^{1}$, Raghvendra Pratap Chaudhary ${ }^{2}$, Sagar Hosangadi Prutvi ${ }^{1}$ and Dipti Guptal*

${ }^{1}$ Plastic Electronics and Energy Laboratory,

Department of Metallurgical Engineering and Materials Science,

Indian Institute of Technology Bombay, India - 400076

${ }^{2}$ Department of Physics \& Astronomy,

Seoul National University, South Korea

Gwanak-gu, Seoul, KR 08826

*E-mail: diptig@,iitb.ac.in

Table S1. Existing PDMS sponge fabrication techniques for versatile applications

\begin{tabular}{|c|c|c|c|}
\hline Application & Step 1 & Step 2 & Remarks \\
\hline $\begin{array}{ll}\text { Oil } \quad- & \text { water } \\
\text { separation[1] } & \end{array}$ & $\begin{array}{l}\text { Sugar cube template } \\
\text { infiltrated } \\
\text { PDMS }\end{array}$ & $\begin{array}{l}\text { Leach off sugar } \\
\text { cube in hot water }\end{array}$ & Porosity defined by template \\
\hline $\begin{array}{lll}\text { Oil } \quad- & \text { water } \\
\text { separation[2] } & \end{array}$ & $\begin{array}{lr}\text { Diluted } & \text { PDMS } \\
\text { mixed with sugar } \\
\text { particles }\end{array}$ & $\begin{array}{l}\text { Dissolving sugar } \\
\text { particles }\end{array}$ & $\begin{array}{l}\text { Porosity defined by density } \\
\text { of sugar particle }\end{array}$ \\
\hline $\begin{array}{lrr}\begin{array}{l}\text { Impurities } \\
\text { separation }\end{array} & \text { and } & \text { oil } \\
\text { water[3] } & & \end{array}$ & $\begin{array}{l}\mathrm{NaCl} \text { and magnetic } \\
\text { nanoparticles added } \\
\text { to resin }\end{array}$ & $\begin{array}{l}\text { Leaching off the } \\
\mathrm{NaCl} \text { particles }\end{array}$ & $\begin{array}{l}\text { Magnetic properties and } \\
\text { porosity defined by Step } 1\end{array}$ \\
\hline $\begin{array}{l}\text { Heavy metal removal } \\
\text { from water[4] }\end{array}$ & $\begin{array}{l}\text { Sugar cube template } \\
\text { method }\end{array}$ & Sugar cube leaching & $\begin{array}{l}\text { Functionalization done by } \\
\text { dip absorb process }\end{array}$ \\
\hline Energy storage[5] & Sugar cube template & Sugar cube leaching & $\begin{array}{l}\text { Sponge made resistive by dip } \\
\text { dry }\end{array}$ \\
\hline 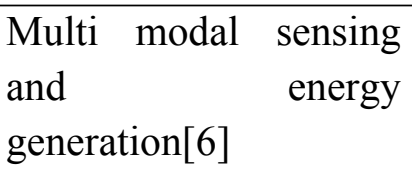 & --------- & ---- & $\begin{array}{l}\text { PDMS spacer and micro- } \\
\text { structuring enabled high } \\
\text { sensitivity }\end{array}$ \\
\hline Photocatalysis[7] & Sugar cube template & Sugar cube leaching & $\begin{array}{l}\text { Porosity imparted by void } \\
\text { space in template }\end{array}$ \\
\hline Microfluidic pumps[8] & Sugar cube template & Template leaching & $\begin{array}{l}\text { Sponge is made hydrophilic } \\
\text { using PVA }\end{array}$ \\
\hline Inlet reservoir[9] & Sugar cube template & Template leaching & $\begin{array}{l}\text { No control on mechanical } \\
\text { stability }\end{array}$ \\
\hline Portable pump[10] & Sugar cube template & Template leaching & $\begin{array}{l}\text { Sponge made hydrophilic } \\
\text { using surfactant }\end{array}$ \\
\hline Capacitive sensor[11] & $\begin{array}{l}\text { Yeast mediated } \\
\text { effervescence }\end{array}$ & $-\cdots$ & 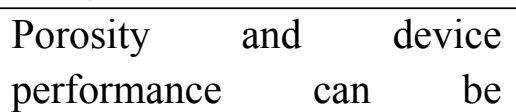 \\
\hline
\end{tabular}




\begin{tabular}{|l|l|l|l|}
\hline & & $\begin{array}{l}\text { controlled but sponge is } \\
\text { hydrophobic }\end{array}$ \\
\hline
\end{tabular}

Table S2. A comparative study of existing resistive sensors; their fabrication process, hydrophilising agent and sensitivity.

\begin{tabular}{|c|c|c|c|}
\hline Material used & $\begin{array}{c}\text { Step 1 } \\
\text { (obtaining sponge) }\end{array}$ & $\begin{array}{c}\text { Step 2 } \\
\text { (making it hydrophilic) }\end{array}$ & $\begin{array}{l}\text { Sensitivity } \\
\left(\mathrm{GF} / \mathrm{kPa}^{-1}\right)\end{array}$ \\
\hline $\begin{array}{c}\text { 3D patterned } \\
\text { PDMS/CNT[12] }\end{array}$ & PnP assisted 3D PDMS & UV/Ozone & 24-134 GF \\
\hline $\begin{array}{l}\text { PU sponge- } \\
\text { CNT[13] }\end{array}$ & Commercial PU sponge & $\begin{array}{l}\text { GO dipped PU sponge } \\
\text { reduced in HI }\end{array}$ & $0.26 \mathrm{kPa}^{-1},<3 \mathrm{kPa}$ \\
\hline $\begin{array}{l}\text { PDMS sponge- } \\
\text { CNT[14] }\end{array}$ & Sugar cube & functionalized CNT & $\begin{array}{l}-- \\
-1\end{array}$ \\
\hline $\begin{array}{l}\text { PU sponge-Carbon } \\
\text { black }(\mathrm{CB})[15]\end{array}$ & Commercial PU sponge & $\begin{array}{l}\text { Natural polymer aided } \\
\text { controlled dispersion of } \\
\text { CB in water }\end{array}$ & $0.068 \mathrm{kPa}^{-1}$ \\
\hline $\begin{array}{l}\text { Sponge-CNT, Ag } \\
\text { NPs[16] }\end{array}$ & Commercial sponge & $\begin{array}{c}\text { SDBS surfactant } \\
\text { stabilized CNT-Ag NP } \\
\text { solution }\end{array}$ & $2.12 \mathrm{kPa}^{-1}, 2.24-11 \mathrm{kPa}$ \\
\hline $\begin{array}{l}\text { PU sponge- } \\
\text { Graphene[17] }\end{array}$ & Commercial sponge & $\begin{array}{l}\text { Hydrothermal reduction of } \\
\text { GO over PU sponge }\end{array}$ & $0.75 \mathrm{kPa}^{-1}$ \\
\hline $\begin{array}{l}\text { PDMS sponge - } \\
\text { CNF-GO[18] }\end{array}$ & Sugar crystal template & Oxygen plasma & $6.4 \mathrm{GF}$ \\
\hline PDMS-CNT[19] & $\begin{array}{l}\text { Ozone treated } \\
\text { microstructures }\end{array}$ & UV/ozone & $\begin{array}{c}-0.101 \pm 0.005 \mathrm{kPa}^{-1} \\
7 \mathrm{~Pa}-50 \mathrm{kPa}\end{array}$ \\
\hline PDMS-CNT[20] & Sugar cube & CNT dispersed in ethanol & $\begin{array}{c}0.3 \mathrm{kPa}^{-1},<1 \mathrm{kPa} \\
0.9 \mathrm{kPa}^{-1}, 15-50 \mathrm{kPa}\end{array}$ \\
\hline $\begin{array}{l}\text { Hydrophillic } \\
\text { PDMS sponge - } \\
\text { conductive paint } \\
\text { (this work) }\end{array}$ & $\begin{array}{l}\text { Yeast autolysis based } \\
\text { effervescence along with } \\
\text { PDMS-b-PEO gives } \\
\text { hydrophilic sponge }\end{array}$ & & $\begin{array}{c}0.3 \mathrm{kPa}^{-1}<10 \mathrm{kPa} \\
0.02 \mathrm{kPa}^{-1}<60 \mathrm{kPa}\end{array}$ \\
\hline
\end{tabular}

\section{Porosity control with curing temperature}

Equal amount of PDMS with $0.5 \mathrm{~g} / 3 \mathrm{~mL}$ yeast - DI water solution is prepared and $0.5 \mathrm{~mL}$ of it is added to the mixture along with $4 \mathrm{wt} \%$ of surfactant. The curing temperature is varied as $80{ }^{\circ} \mathrm{C}, 100{ }^{\circ} \mathrm{C}$, $120^{\circ} \mathrm{C}$ and $140^{\circ} \mathrm{C}$. For lower temperature, longer duration was provided for complete sponge formation. Fig. S1 shows the morphology and porosity variations observed. At low temperature, insufficient heat causes uncured PDMS to fall back into ripening pore contours giving solid rather porous features hindering 
porosity generation in the medium. At higher curing temperatures, simultaneous PDMS curing with effervescence enable formation of fine pores.
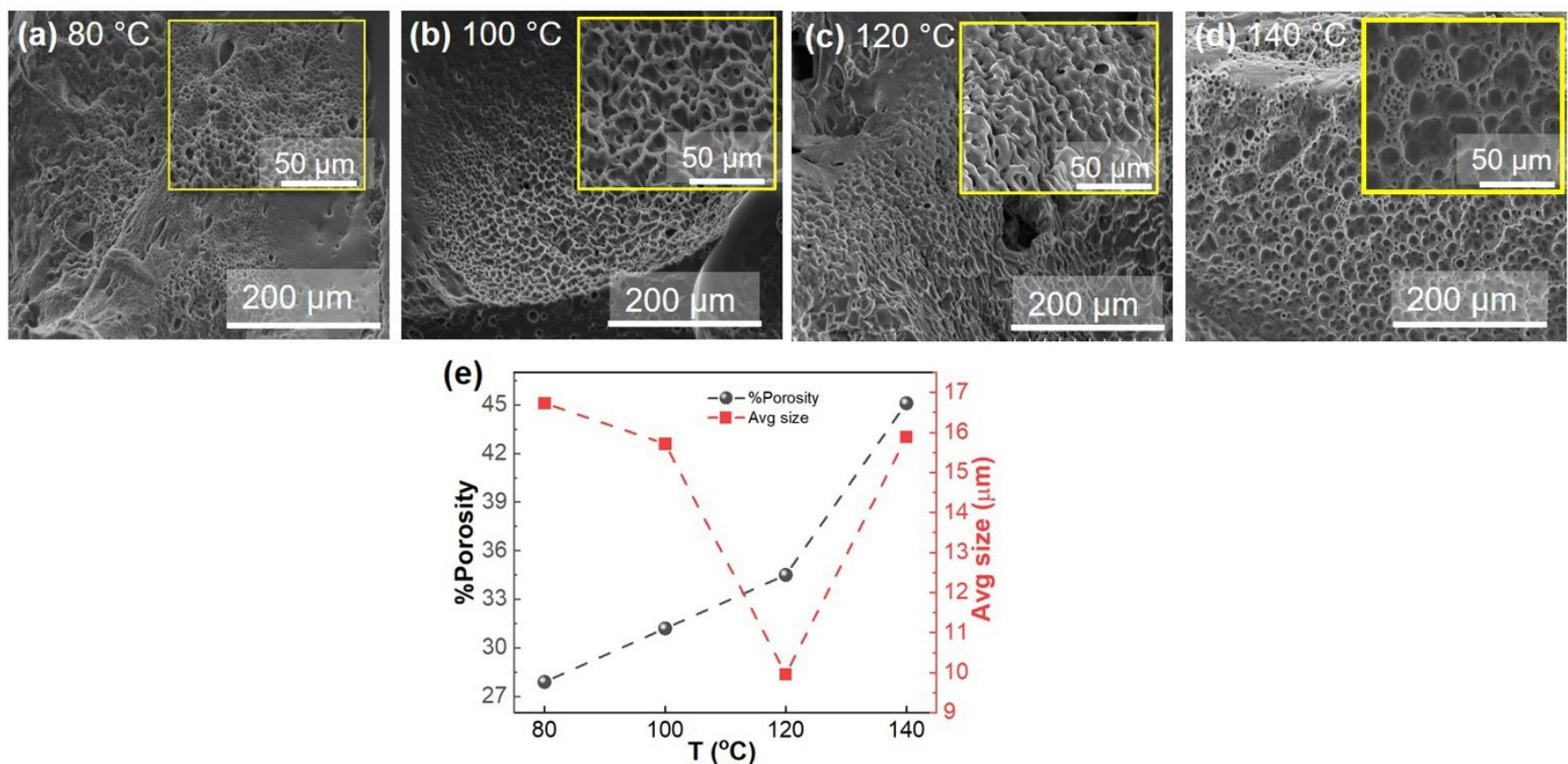

Fig. S1. (a) - (d) SEM images of sponge showing effect of curing temperature on morphology (e) Variation of pore size and \%Porosity

\section{Mechanical property comparison of hydrophobic and obtained hydrophilic PDMS sponge}

Fig. S2 below shows the stress vs strain plot showing the extended linear range of stress strain curve showing the linear region for productive sensing possible. The applied strain and Young's modulus generated in the sponge at different strain regimes show that as increased pressure is applied, the porous entity exhibits bulk behavior with higher modulus which restricts its operation window as a sensor. An increase in the linear range is observed for the hydrophilic sponges. Plateau region shows an enhancement from 1 to 1 ' in hydrophilic sponge showing continuous deformation phase where the sponge collapses with the strands of pores getting bend. Region from 2 to $2^{\prime}$ is the continuous densification stage where the sponge behaves as a compact solid and the stress increases at a higher rate with strain giving an increased Young's modulus in this region. The better chemistry of PEO moieties with the hydrophobic PDMS results in forming better distribution of yeast with the hydrophobic PDMS heads and hydrophilic PEO tails joining the PDMS and water precursors. An overall 30\% enhancement in the operational region of the mechanical property of the sponge is thus obtained with the cell collapse and compact solid regimes [21]. 


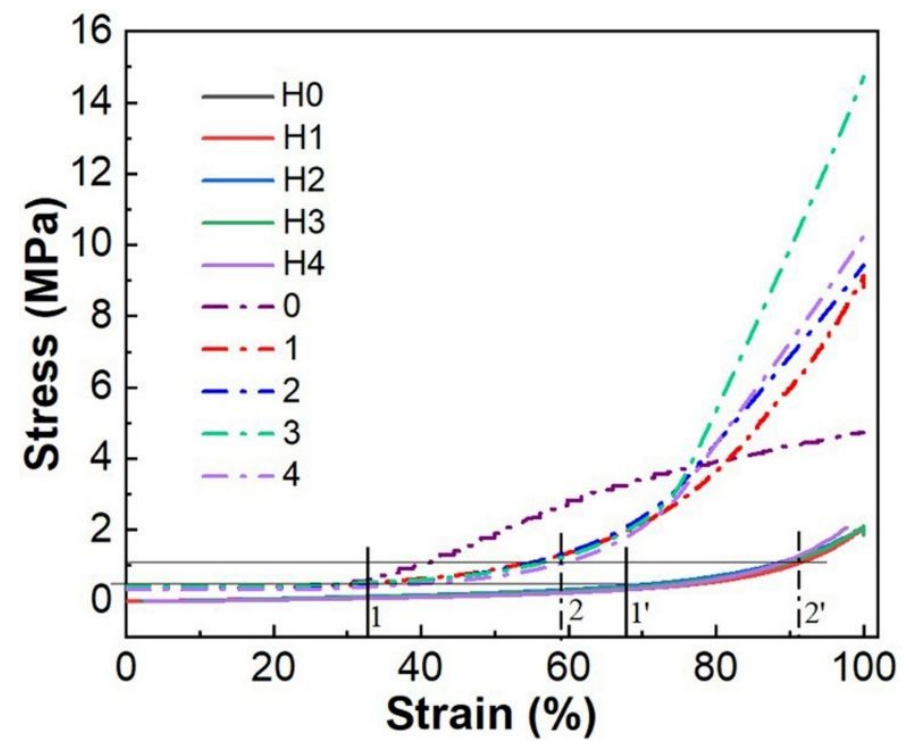

Fig. S2. Stress vs Strain plot of porous PDMS hydrophobic (dotted lines 0 to 4 in legend denoted yeast concentration in $3 \mathrm{~mL}$ DI water) and hydrophilic (solid lines, H0 to H4 in legend denotes yeast concentration in 3 $\mathrm{mL}$ DI water) sponges.

\section{Extended capacitive pressure sensor}

The surfactant being inherently hydrophilic facilitates better dispersion of yeast solution in the base resin. This leads to uniform effervescence giving more homogeneous pores further enabling more resilience to the sponge as seen from Fig. S3. This provides lower Young's modulus and larger linear range for sensing the applied pressure. The larger operational window is facilitated by the finer pore distribution at the millimeter scale rather the micro pores observed from the electron microscope images as seen in above sections. Analyzing the elasticity of the sponge provides further insights into the improved active pressure region. The sponge shows an increase in the linear regime or the constant Young's modulus region which defines the sensing window. The lower modulus over strain upto $\sim 75 \%$ provides an extended active region which is highest achieved yet with an elastomer sponge. For sponge obtained at curing of $120^{\circ} \mathrm{C}$, the linear region extends upto $\sim 100 \mathrm{kPa}$. 

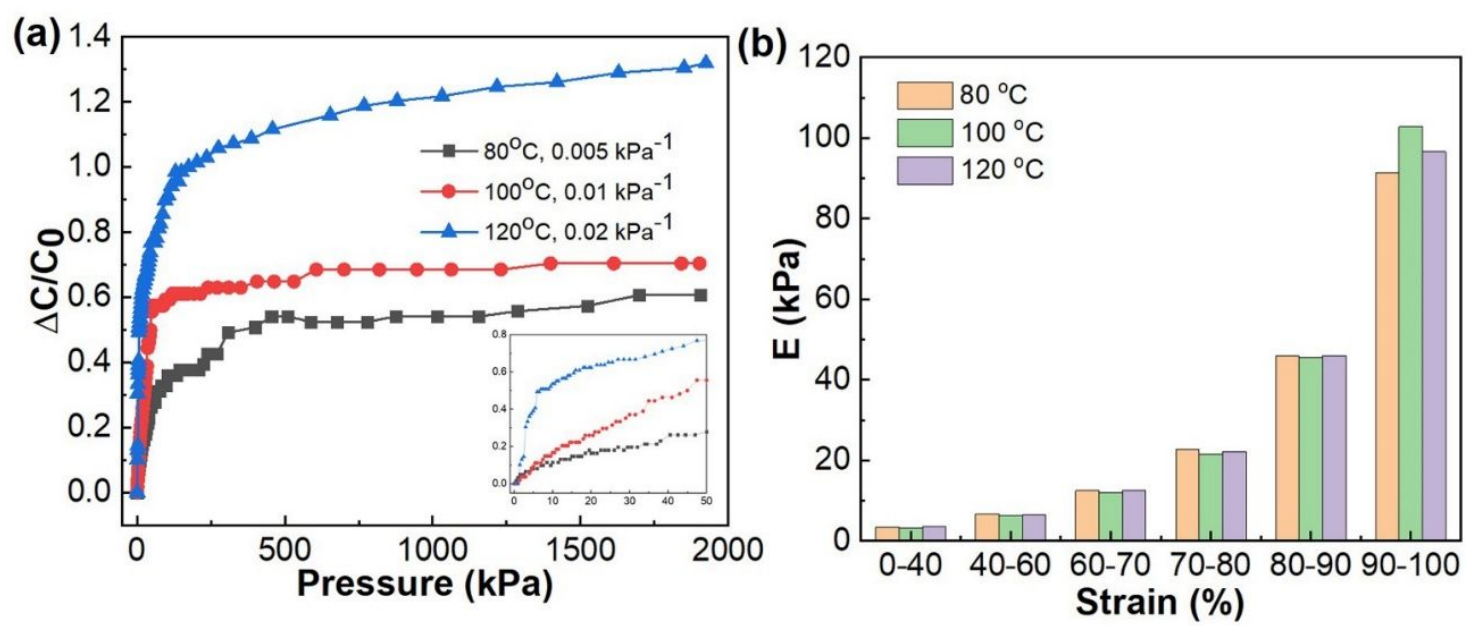

Fig. S3. (a) The capacitive sensor performance along with its extended linear region upto $50 \mathrm{kPa}$ (b) The Young's modulus at different strain regions enabling the linear sensitivity behavior.

\section{Resistive sponge fabrication}

Fig. S4 shows the procedure schematic along with the measurement setup used for electrical parameter assessment. The sponge is placed inside the ink of $1 \mathrm{~g} / 10 \mathrm{~g}$ concentration prepared by weighing $1 \mathrm{~g}$ of the ink and adding $9 \mathrm{~mL}$ of DI water to make the total weight of $10 \mathrm{~g}$. The sample is then placed in a desiccator and vacuum is applied to allow the ink to infiltrate uniformly along the porous structure for 3 hrs. The sponge is then taken out and dried on a hot plate at $70{ }^{\circ} \mathrm{C}$. The process is then repeated to attain a resistance of a few hundred kilo ohms in the intact state of the sponge. The resistive sponge is then attached to copper tape using silver conductive adhesive. Electrical wires are further attached to the copper tape to interface with the measurement setup. MARK 10 tensile instrument is used to apply the compression and the corresponding electrical current is measured for an applied voltage. Resistance is then derived by Ohm's law from the data obtained using the formula

$$
R=\frac{\mathrm{V}}{\mathrm{I}}
$$

where, $\mathrm{V}$ is the applied voltage and $\mathrm{I}$ is the measured current. 
(a) Resistive sponge fabrication

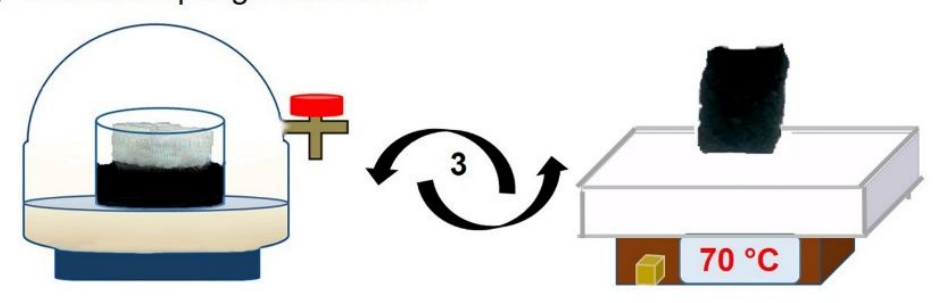

(c) Measurement setup
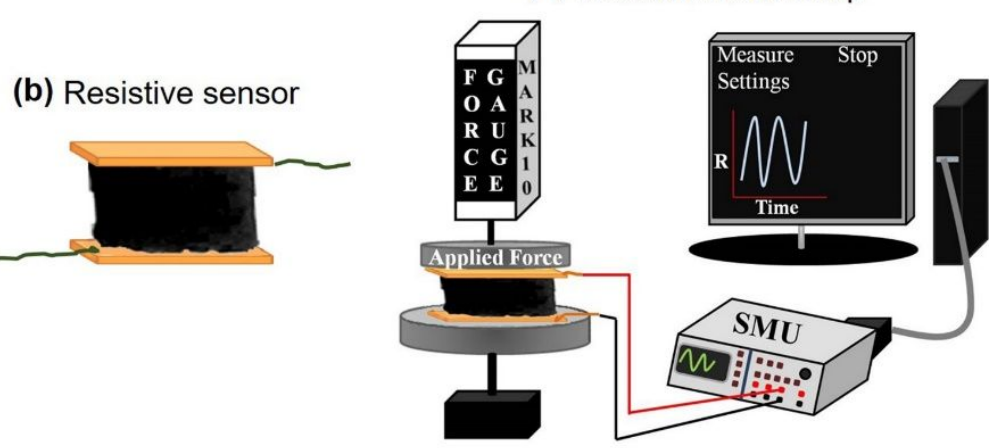

Fig. S4. (a) Schematic of the procedure of making the hydrophilic sponge conductive. The sponge is infiltrated with the conductive ink in a desiccator for $3 \mathrm{hrs}$ and then dried over a hot plate at $70{ }^{\circ} \mathrm{C}$. This is repeated thrice to attain sufficient resistance of the order of $\mathrm{k} \Omega$ in the sponge. (b) The final fabricated resistive sensor with copper electrodes attached for external connections (c) Measurement setup showing the in-situ force application and resistance measurement unit.

\section{Fabrication and characterization of resistive sensor}

The resistive device is characterized for its cyclic stability, load and frequency varied response to confirm its applicability for sensing applications. Fig. S5 (a) shows the response of device for increasing load applied from a standard analytical weight box ( $1 \mathrm{~g}$ to $200 \mathrm{~g}$ ). The resistance falls for higher weights which lead to collapse of the porous structure bringing the conductive strands in the sponge closer thereby reducing the resistance. The stability of sensor to cyclic load is studied from application of constant cyclic load and the response is shown in Fig. S5 (b). The response remains stable even after $\sim 1000$ cycles showing the robust nature of the porous structure obtained. For varied cyclic load, the amplitude variation shows distinct response. The response of device to varied strain is shown in Fig. S5 (c). 

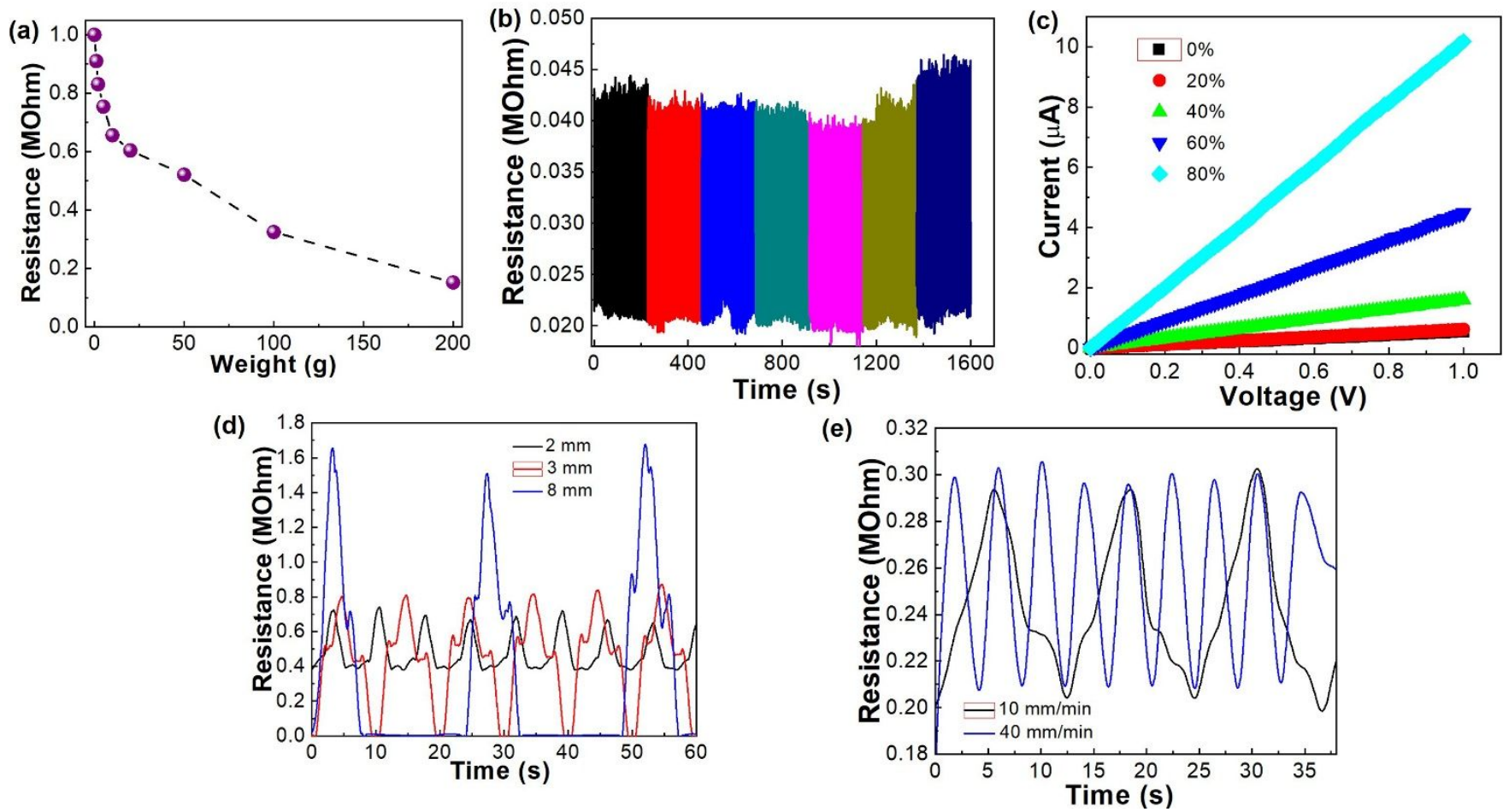

Fig. S5. (a) Resistance plot corresponding to different weights showing the sensitive nature of resistive sponge. (b) Cyclic response showing the response to the cyclic pressure applied. Each color shows a set of 100 cycles. (c)

Response of resistive sponge to different applied stress. (d) Response to different loads. (e) Response to varied speed for same applied pressure.

Here the device is subjected to different compression levels for strain from $0 \%$ to $80 \%$ and their static response at these strains is recorded. With increase in applied strain the current increases which shows a decrease in resistance. An Ohmic behavior is inferred which essentially shows the resistive nature of the sensor. The cyclic response to different strain and load of the sensor shows the reliable and susceptible nature of it. This quick response is enabled by the resilient nature of the sponge with little hysteresis in porosity and pore area.

\section{Sensing mechanism of sensor}

The sensing action of sensors is due to change in the electrical property arising from the compression of sponge (Fig. S6). As a capacitive sensor, the densification of material causes reduction in distance between the parallel conducting plates giving a higher capacitance for applied pressure. The resistance, on the other hand, in an elastomer sponge arises from the discontinuous contact between the resistive strands of the $3 \mathrm{D}$ porous structure. When a vertical pressure is applied, pores collapse reducing the gap between the resistive strands providing a shorter conducting path reducing the resistance of the overall structure. This results in the transduction of applied mechanical pressure into electrical signal giving a highly efficient resistive pressure sensor (Fig. S6 (a) - (f)). On the contrary when the strands are pulled 
apart increasing the gap between them and causing an increase in the resistance of the overall device acting as a tactile sensor (Fig. S6 (g) - (j)). These define the sensing activity enabled in the device by virtue of the porous nature of the elastomer sponge. With simple resistance variation mechanism, our resistive sponge can be used both as a pressure sensor as well as a tactile sensor by changing the direction of applied stimulus.

(a)

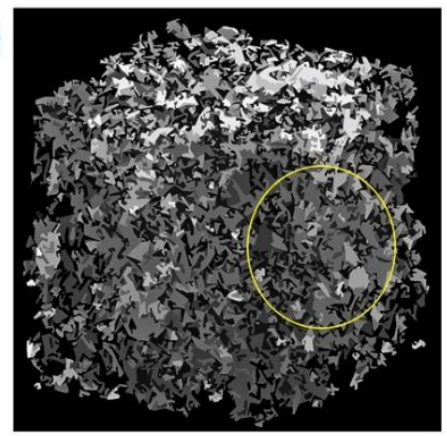

(b)

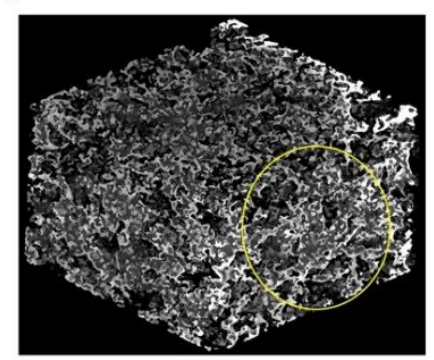

(c)

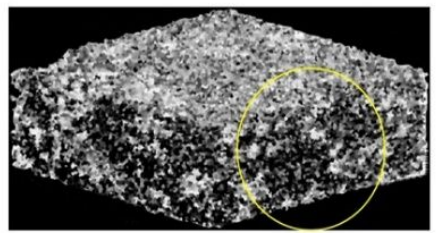

(d)

Denser conductive elements in the compressed volume causes lower resistance

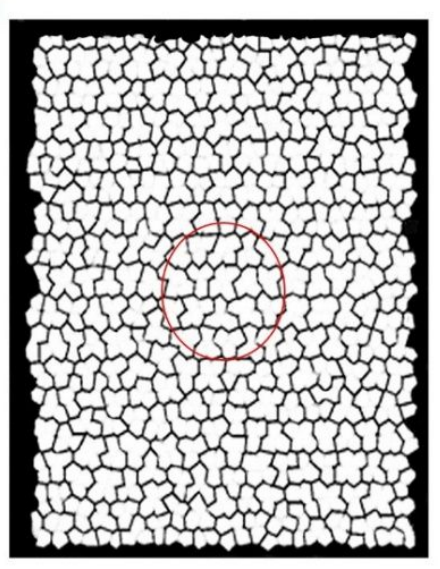

(e)

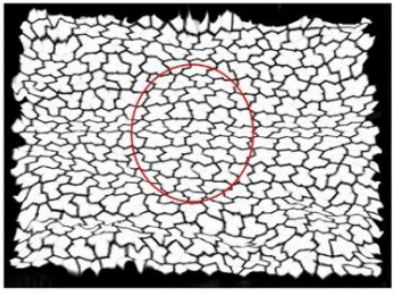

(f)

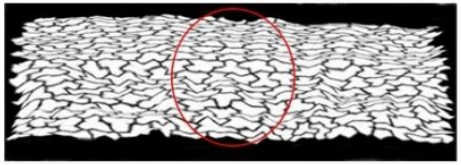

(g)

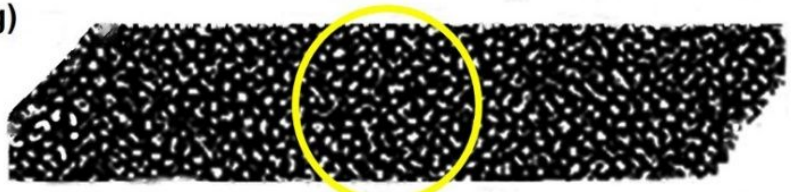

(i)

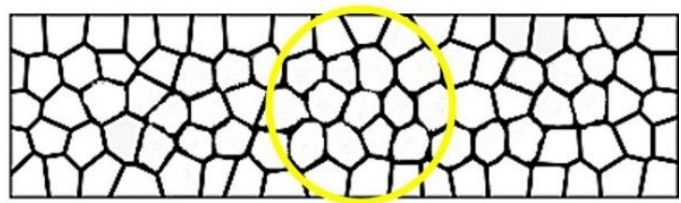

(h)

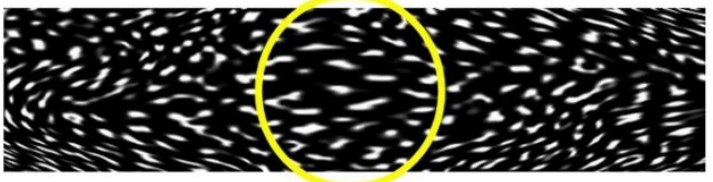

(j)

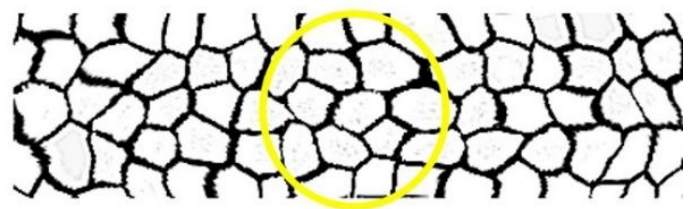

With application of linear strain the conducting strands get elongated giving an increase in the resistance in the path

Fig. S6. (a) - (f) Sponge skeletons consisting of the pores with the conducting strands. When a pressure is applied, pore gap decreases and the net density of conducting elements increases decreasing the resistance. (g) - (j) Sponge skeleton schematic showing the elongated pores in (h) compared to (g). (i) - (j) Schematic of increase in distance between the strands (j) compared to (i) thereby increasing the resistance of the device. 


\section{Resistive sensor applications}

The fabricated single device is applied as a sensor in both the tactile and pressure sensing modes for a wide window of pressure range from pulse pressure to plantar pressure as shown in Fig. S7.
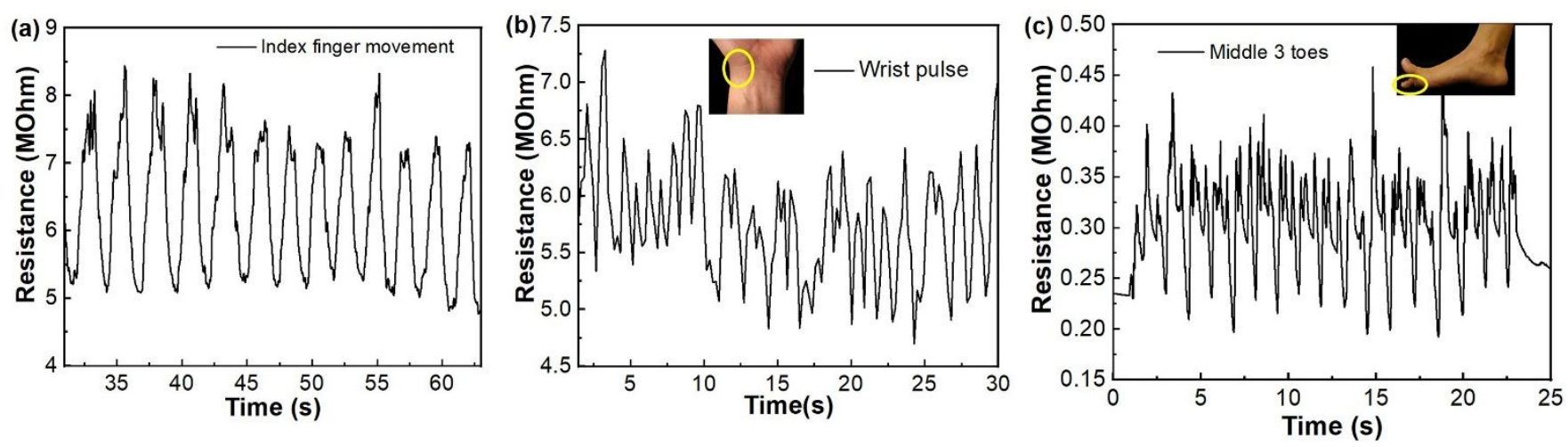

Fig. S7. (a) Tactile sensing at index finger periodic bending motion (b) wrist pulse pressure measurement (c) plantar pressure measured at toe contact during a walk sequence.

\section{Supercapacitor performance evaluation}

Capacitance of the device is calculated from the CV curve using equation SEq2:

$$
C=\frac{\int I(V) d v}{k m \Delta V}
$$

Where, $\mathrm{C}$ is the calculated gravimetric capacitance $(\mathrm{F} / \mathrm{g}), \mathrm{I}(\mathrm{V})$ is the current as function of voltage, $\mathrm{k}$ is the scan rate in $\mathrm{mV} / \mathrm{s}, \mathrm{m}$ is the weight of active carbon $(\mathrm{g})$ in the resistive sponge which is calculated from weight of sponge before and after dip and dry process, $\Delta \mathrm{V}$ is the voltage window of operation $(\mathrm{V})$.

\section{Machine-Human interface}

The circuit employed for each pixel is as shown in the Fig. S8. 


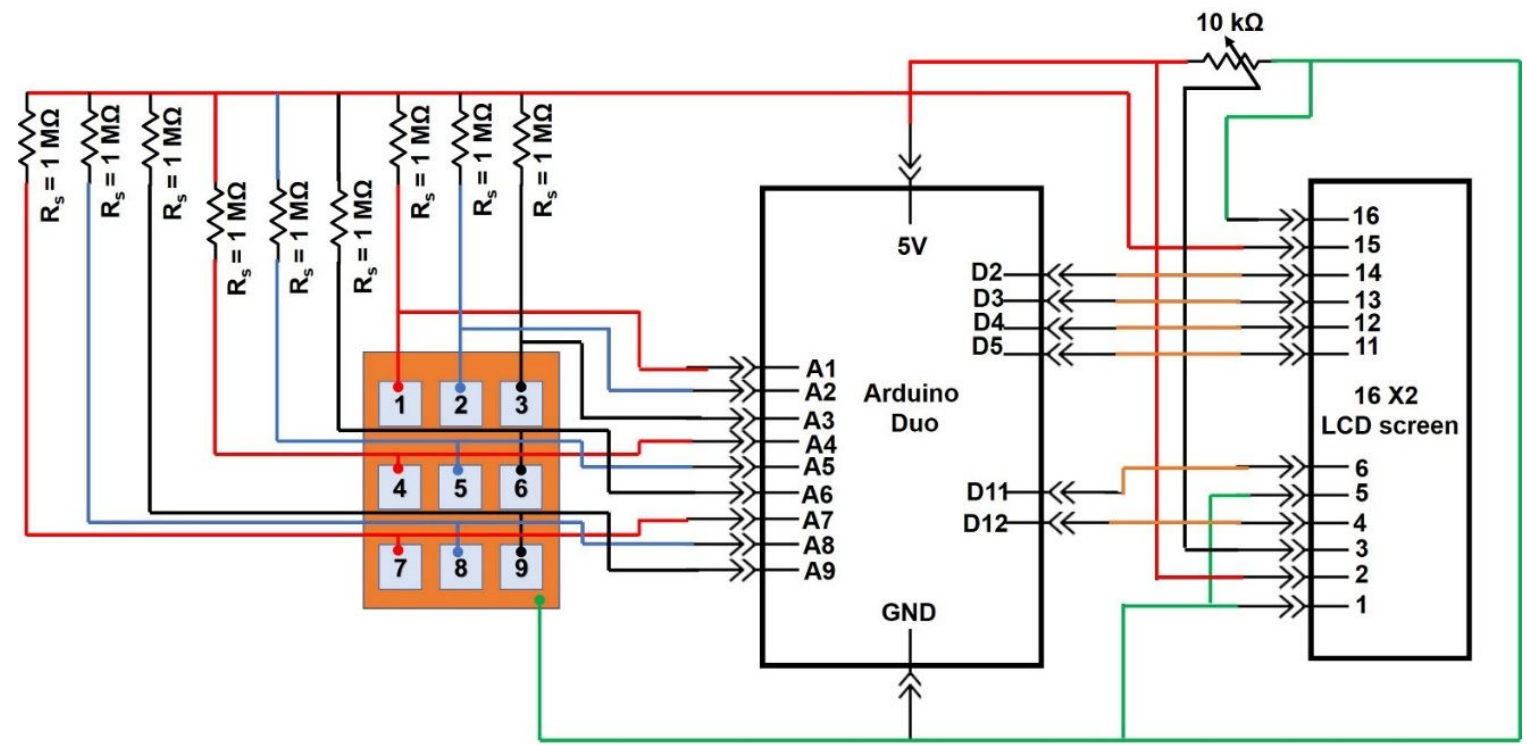

Fig. S8. Circuit for real time number display using resistive sponge as number elements and Arduino for interfacing with LCD (image reference-arduino open source help) [22]

Fig. S8 shows the complete circuit implemented for real time number display on the LCD. Video 1 shows a glimpse of the display for a complete cycle of events.

\section{Sample preparation for FTIR}

Thin film samples of PDMS-b-PEO were prepared. PDMS base to curing agent in the ratio 10 to 1 is taken and $4 \%$ by weight of PDMS-b-PEO is added and mixed thoroughly. It is then poured on a glass slide and cured at $70{ }^{\circ} \mathrm{C}$ for $3 \mathrm{hrs}$. It is then peeled off to form a free standing film. A thin layer is cut out from the elastomer sponge to form a thin film. Yeast granules as received are crushed with $\mathrm{KBr}$ to form a pellet.

\section{References:}

[1] Choi, S.J.; Kwon, T.H.; Im, H.; Il M. D.; Baek, D.J.; Seol, M.L.; Duarte, J.P.; Choi, Y.K. A polydimethylsiloxane (PDMS) sponge for the selective absorption of oil from water. ACS Appl. Mater. Interfaces. 2011, 3, 4552-4556.

[2] Zhang, A.; Chen, M.; Du, C.; Guo, H.; Bai, H.; Li, L. Poly(dimethylsiloxane) Oil Absorbent with a Three-Dimensionally Interconnected Porous Structure and Swellable Skeleton. Appl. Mater. Interfaces. 2013, 5, 10201-10206.

[3] Wang, X.; Lu, Y.; Carmalt, C.J.; Parkin, I.P.; Zhang, X. Multifunctional Porous and Magnetic Silicone with High Elasticity, Durability, and Oil-Water Separation Properties. Langmuir, 2018, 34, 13305-13311.

[4] Chavan, A.A.; Li, H.; Scarpellini, A.; Marras, S.; Manna, L.; Athanassiou, A.; Fragouli, D. Elastomeric Nanocomposite Foams for the Removal of Heavy Metal Ions from Water. ACS Appl. Mater. Interfaces. 2015, 7, 14778-14784.

[5] Song, Y.; Chen, H.; Su, Z.; Chen, X.; Miao, L.; Zhang, J.; Cheng, X.; Zhang, H. Highly 
Compressible Integrated Supercapacitor-Piezoresistance-Sensor System with CNT-PDMS Sponge for Health Monitoring. Small, 2017,13, 1-10.

[6] Park, S.; Kim, H.; Vosgueritchian, M.; Cheon, S.; Kim, H.; Koo, J.H.; Kim, T.R.; Lee, S.; Schwartz, G.; Chang, H.; Bao, Z. Stretchable Energy-Harvesting Tactile Electronic Skin Capable of Differentiating Multiple Mechanical Stimuli Modes. Adv. Mater. 2014, 26, 7324-7332.

[7] Li, X.; Li, Y.; Huang, Y.; Zhang, T.; Liu, Y.; Yang, B.; He, C.; Zhou, X.; Zhang, J. Organic sponge photocatalysis. Green Chem. 2017, 19, 2925-2930.

[8] Zhou, T.; Yang, J.; Zhu, D.; Zheng, J.; Handschuh-Wang, S.; Zhou, X.; Zhang, J.; Liu, Y.; Liu, Z.; He, C.; Zhou, X. Hydrophilic Sponges for Leaf-Inspired Continuous Pumping of Liquids. Adv. Sci. 2017,4, 6 .

[9] Cha, K.J.; Kim, D.S. A portable pressure pump for microfluidic lab-on-a-chip systems using a porous polydimethylsiloxane (PDMS) sponge. Biomed. Microdevices. 2011, 13, 877-883.

[10] Yang, W.; Nam, Y.G.; Lee, B.K.; Han, K.; Kwon, T.H.; Kim, D.S. Fabrication of a hydrophilic poly(dimethylsiloxane) microporous structure and its application to portable microfluidic pump, Jpn. J. Appl. Phys. 2010,49.

[11] Parameswaran, C.; Gupta, D.; Low cost sponge based piezocapacitive sensors using a single step leavening agent mediated autolysis process. J. Mater. Chem. C. 2018, 6, 5473-5481.

[12] Cho, D.; Park, J.; Kim, J.; Kim, T.; Kim, J.; Park, I.; Jeon, S. Three-Dimensional Continuous Conductive Nanostructure for Highly Sensitive and Stretchable Strain Sensor. ACS Appl. Mater. Interfaces. 2017, 9, 17369-17378.

[13] Yao, H. B.; Ge, J.; Wang, C.F.; Wang, X.; Hu, W.; Zheng, Z.J.; Ni, Y.; Yu, S.H. A flexible and highly pressure-sensitive graphene-polyurethane sponge based on fractured microstructure design. Adv. Mater. 2013, 25, 6692-6698.

[14] Han, J.W.; Kim, B.; Li, J.; Meyyappan, M. Flexible, compressible, hydrophobic, floatable, and conductive carbon nanotube-polymer sponge, Appl. Phys. Lett. 2013, 102.

[15] Wu, X.; Han, Y.; Zhang, X.; Zhou, Z.; Lu, C. Large-Area Compliant, Low-Cost, and Versatile Pressure-Sensing Platform Based on Microcrack-Designed Carbon Black@Polyurethane Sponge for Human-Machine Interfacing. Adv. Funct. Mater. 2016, 26, 6246-6256.

[16] Zhang, H.; Liu, N.; Shi, Y.; Liu, W.; Yue, Y.; Wang, S.; Ma, Y.; Wen, L.; Li, L.; Long, F.; Zou, Z.; Gao, Y. Piezoresistive Sensor with High Elasticity Based on 3D Hybrid Network of Sponge@CNTs@Ag NPs.ACS Appl. Mater.Interfaces. 2016, 8, 22374-22381.

[17] Luo, Y.; Xiao, Q.; Li, B. Highly compressible graphene/polyurethane sponge with linear and dynamic piezoresistive behavior. RSC Adv. 2017, 7, 34939-34944.

[18] Wu, S.; Zhang, J.; Ladani, R.B.; Ravindran, A.R.; Mouritz, A.P.; Kinloch, A.J.; Wang, C.H. Novel Electrically Conductive Porous PDMS/Carbon Nanofiber Composites for Deformable Strain Sensors and Conductors. ACS Appl. Mater. Interfaces. 2017, 9, 14207-14215.

[19] Yu, G.; Hu, J.; Tan, J.; Gao, Y.; Lu, Y.; Xuan, F. A wearable pressure sensor based on ultraviolet/ozone microstructured carbon nanotube/polydimethylsiloxane arrays for electronic skins. Nanotechnology, 2018, 29.

[20] Iglio, R.; Mariani, S.; Robbiano, V.; Strambini, L.; Barillaro, G. Flexible Polydimethylsiloxane Foams Decorated with Multiwalled Carbon Nanotubes Enable Unprecedented Detection of Ultralow Strain and Pressure Coupled with a Large Working Range. ACS Appl. Mater. Interfaces. 2018,10, 13877-13885.

[21] Ouellet, S.; Cronin, D.; Worswick, M. Compressive response of polymeric foams under quasi-static, medium and high strain rate conditions. Polym. Test. 2006, 25, 731-743.

[22] No Title, (n.d.). https://learning.grobotronics.com/el/2013/10/controlling-lcd-displays-8x2-raystar/. 